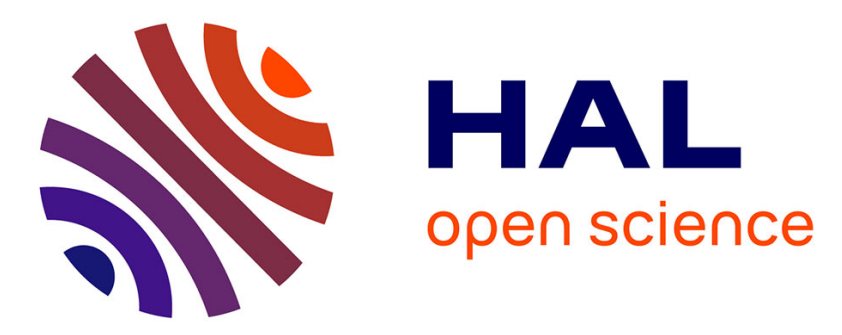

\title{
Continuous flow catalysis with a biomimetic copper(II) complex covalently immobilized on graphite felt
}

\author{
Ronan Marion, Gopinathan Muthusamy, Florence Geneste
}

\section{To cite this version:}

Ronan Marion, Gopinathan Muthusamy, Florence Geneste. Continuous flow catalysis with a biomimetic copper(II) complex covalently immobilized on graphite felt. Journal of Catalysis, 2013, 286, pp.266-272. 10.1016/j.jcat.2011.11.011 . hal-00842808

\section{HAL Id: hal-00842808 \\ https://hal-univ-rennes1.archives-ouvertes.fr/hal-00842808}

Submitted on 9 Jul 2013

HAL is a multi-disciplinary open access archive for the deposit and dissemination of scientific research documents, whether they are published or not. The documents may come from teaching and research institutions in France or abroad, or from public or private research centers.
L'archive ouverte pluridisciplinaire HAL, est destinée au dépôt et à la diffusion de documents scientifiques de niveau recherche, publiés ou non, émanant des établissements d'enseignement et de recherche français ou étrangers, des laboratoires publics ou privés. 
Continuous flow catalysis with a biomimetic copper(II) complex covalently immobilized on graphite felt

Ronan Marion, Gopinathan Muthusamy, Florence Geneste*

Université de Rennes 1, UMR-CNRS 6226, Laboratoire des Sciences Chimiques de Rennes, Equipe Matière Condensée et Systèmes Electroactifs, Campus de Beaulieu, 35042 Rennes cedex, France

\begin{abstract}
The catecholase activity of a copper(II) complex coordinated by a tripodal pyrazole-based ligand was investigated in continuous flow catalysis. The covalent immobilization of the complex on the surface was achieved by a two steps method. First the porous graphite felt support is functionalized by electrochemical reduction of 4-carboxymethyl-benzenediazonium salts. Second the complex is covalently immobilized by esterification reaction between the $\mathrm{COOH}$-containing linker and a primary alcohol group present on the C6 chain of the ligand. The two steps of the immobilization process were optimized by using nitro-containing molecules and cyclic voltammetry analyses. The copper complex exhibits higher catecholase activity in continuous flow catalysis than in solution with a 50 times lower amount of catalyst, underlining the advantages of the flow procedure. The presence of $\mathrm{H}_{2} \mathrm{O}_{2}$ is detected after catalysis, showing that the four-electron reduction of dioxygen to water does not occur unlike the natural enzyme.
\end{abstract}

Keywords Catechol oxidase, biomimetic, flow, heterogeneous catalysis, copper complex, diazonium salts, graphite felt, $N$-tripodal ligand

\title{
1. Introduction
}

Oxidation reactions have a crucial role in organic synthesis and industrial processes and the research of new catalysts in this area is always in progress. For this purpose a large diversity

\footnotetext{
${ }^{*}$ Corresponding author. Fax : +33 223235967

E-mail address : Florence.Geneste@univ-rennes1.fr
} 
of biomimetic catalysts has been studied, since nature is able with enzymes to achieve efficient and selective oxidations. For example, copper complexes are used to mimic the active site of type-3 copper proteins such as hemocyanin, an oxygen-transport protein, tyrosinase and catechol oxidase that use dioxygen to catalyze the oxidation of phenols and $o$ diphenols to $o$-quinone, respectively $[1,2]$. The active site of these enzymes contains a dinuclear $\mathrm{Cu}-\mathrm{Cu}$ center with each copper coordinated by three imidazoles from the histidine residues (Scheme 1) [3, 4].

\section{Scheme 1}

However, biomimetic molecular catalysts are often less stable and selective than enzymes whose active site is isolated in a protein matrix. To improve their performances and closely mimic the natural enzymes, molecular catalysts have been immobilized on supports [5-24]. The aim is to provide proper geometry and distance for catalytic centers, and to enhance its stability, reducing the possibility of side reactions to occur. Moreover, the immobilization of the catalyst on a support leads to an improvement of the catalytic process, avoiding problems linked to the solubility of the catalyst in the reaction medium and facilitating the recovery of the catalyst and the purification step.

Thus mono and dinuclear copper complexes have been covalently immobilized on $\mathrm{SiO}_{2}$ [5-8]. The grafted catalysts have shown significantly higher catecholase activity than when they are dissolved in solution. Interestingly, it has been noticed that the coordination of the metal can be different when the ligand is immobilized on a support. Thus, with bidentate ligands, the authors have shown by EPR spectroscopy that the coordination of $\mathrm{Cu}^{2+}$ depends on the loading of the immobilized ligands on the support [5]. High loading led to the coordination of $\mathrm{Cu}^{2+}$ to four nitrogens of two closed bidentate ligands and resulted in short $\mathrm{Cu}-\mathrm{Cu}$ distances, which was responsible for the improved catalytic activity.

Encapsulation of copper complexes in porous solid materials has also been investigated. Thus mesoporous silicas and zeolites have been envisioned as an equivalent to the backbone of the protein skeleton of natural biological systems [9-12, 16-19, 22-24]. The difficulty of these porous systems is that the pore size has to match the catalyst: too small pores will prevent the incorporation of effective ligand or the diffusion of the substrate and too large pores lead to less confinement effect in protecting the copper complex from leaching into the reaction media. However, when the size of the pores is convenient the authors observed improvement 
of the catecholase activity for encapsulated complex compared with the same complexes in solution. Copper complexes have also been immobilized by adsorption or covalent bonding on polymers $[14,15,20,21]$. Even there, heterogeneous catalysis gave better results than when the catalyst is in solution.

Our laboratory has been using graphite felt for applications in continuous flow redox catalysis and has developed methods to functionalize this material for the covalent immobilization of catalysts on this support [25-32]. The characteristics of this material such as a high void volume, a large geometric surface area and a good homogeneity of the fibres repartition inside the felt makes it especially interesting for heterogeneous catalysis. The opportunity to employ this support in continuous flow process is also a particularly important feature because it makes easier the automation and industrial development of solution phase synthesis [33-36]. Furthermore, in the flow system a small amount of the substrate is actually forced into intimate contact with an "excess" of catalyst favouring higher conversions and lower reaction time.

We have previously prepared mononuclear copper complexes based on tripodal ligands with pyrazole rings and containing a functionalized chain [37]. The complexes have shown good catalytic activity toward the oxidation of 3,5-di-tert-butylcatechol, especially with unsubstituted pyrazole rings and a long alkyl chain. We report here the covalent immobilization of the most effective copper complex of this series on graphite felt and its catecholase activity in continuous flow catalysis. Comparison with the reaction performed in the same conditions but with the catalyst dissolved in solution will highlight the interest of the supported process.

\section{Experimental section}

\subsection{Reagents and materials}

Graphite felt was obtained from Le Carbone Lorraine (RVG 4000). 4-nitrobenzenediazonium salts, 4-nitrobenzyl alcohol, diethylaminosulfur trifluoride (DAST), thionyl chloride, oxalyl chloride and anhydrous copper(II) chloride were purchased from Aldrich or ACROS and used as supplied. All solvents were analytical grade. Tetrahydrofuran (THF) was distilled from deep blue solutions of sodium/benzophenone ketyl prior to use. Syntheses of the tripodal ligand and the corresponding copper complex have been previously described [37]. 4- 
Carboxymethyl-benzenediazonium salts were prepared according to literature and stored under argon in a freezer [38].

\subsection{Instrumentation}

Controlled potential electrolyses were performed in a divided flow cell, fitted with a graphite felt electrode (10 mm diameter, $10 \mathrm{~mm}$ thickness) located between two counter electrodes $[31,39]$. Two cationic exchange membranes (Ionac 3470) were used for cell division. The reference electrode (Saturated Calomel Electrode, SCE) was positioned at the surface of the felt, at an equal distance from the entry to the exit of the porous electrode. Voltammetric experiments were carried out using an EDAQ potentiostat unit, with the EChem software package. A platinum wire working electrode, a platinum wire auxiliary electrode, and a saturated calomel reference electrode were used in a standard three-electrode configuration. The graphite felt sample $\left(\sim 1 \mathrm{~cm}^{3}\right)$ was fixed to the platinum wire before analysis. Cyclic voltammetry analyses of immobilized complexes were performed in acetonitrile containing $0.1 \mathrm{M}$ tetrabutylammonium hexafluorophosphate, under a dinitrogen atmosphere. The electrodes modified by nitro compounds were analyzed in degassed $\mathrm{H}_{2} \mathrm{SO}_{4} 0.5 \mathrm{~mol} \mathrm{~L}^{-1}$ under nitrogen. First, electroreduction of the nitro groups into hydroxylamines was performed by cycling the potential twice between 0 and $-0.5 \mathrm{~V}_{\mathrm{SCE}}$ at $0.1 \mathrm{~V} \mathrm{~s}^{-1}$ and then, the nitrosohydroxylamine reversible system (Fig. 1a) was observed by cycling the potential between 0 and $0.5 \mathrm{~V}_{\text {SCE. }}$

Figure 1

\subsection{Preparation of the modified graphite felts}

\section{Electrochemical functionalization of the graphite felt}

$100 \mathrm{mg}$ of 4-nitrophenyldiazonium salts or 4-carboxymethylbenzenediazonium salts, dissolved in $100 \mathrm{~mL}$ of degassed $\mathrm{H}_{2} \mathrm{SO}_{4}$ or $\mathrm{HCl} 0.5 \mathrm{M}$ were reduced at $-0.2 \mathrm{~V}_{\mathrm{SCE}}$ for $5 \mathrm{~min}$ under nitrogen, using a graphite felt (48 mm diameter, $12 \mathrm{~mm}$ thickness) as workingelectrode. Then the derivatized graphite felt was ultrasonicated four times in deionized water for $15 \mathrm{~min}$ and dried under vacuum.

\section{Esterification reaction}

The functionalized graphite felt was placed in $50 \mathrm{~mL}$ anhydrous dichloromethane in a reactor under argon at $0{ }^{\circ} \mathrm{C} .0 .5 \mathrm{~mL}$ of DAST, oxalyl chloride or thionyl chloride were added and the 
solution was stirred at room temperature for $5 \mathrm{~h}$. The felts were rinsed in anhydrous dichloromethane and then dried under vacuum. For the procedure with DAST, the felt was just ultrasonicated two times in dichloromethane. Then, the electrode was placed in a solution of anhydrous dichloromethane, $1 \mathrm{~mL}$ of triethylamine and $100 \mathrm{mg}$ of 4-nitrobenzyl alcohol, tripodal ligand or complex. The solution was stirred at room temperature for 1 day. The modified electrode was ultrasonicated two times in dichloromethane and two times with acetone for $15 \mathrm{~min}$.

\section{Metalation reaction}

A graphite felt modified by the tripodal ligand was placed in a stirred solution of $100 \mathrm{mg}$ of copper(II) chloride in $50 \mathrm{~mL}$ anhydrous THF overnight under argon at room temperature. Then it was ultrasonicated twice in THF and twice in acetone for $15 \mathrm{~min}$.

\subsection{Catalysis}

\section{With the catalyst dissolved in solution}

The experiments were conducted in air at constant stirring and temperature of $25{ }^{\circ} \mathrm{C}$, monitored with a contact thermometer dipped in the solution. Six milliliter of a $1.5 \times 10^{-4} \mathrm{~mol}$ $\mathrm{L}^{-1}$ solution of copper complex in methanol was added under stirring to a fresh solution of $10^{-}$ ${ }^{2} \mathrm{~mol} \mathrm{~L}{ }^{-1}$ of 3,5-di-tert-butylcatechol in $40 \mathrm{~mL}$ methanol maintained at $25{ }^{\circ} \mathrm{C}$. Therefore, the initial concentration of 3,5-di-tert-butylcatechol in the solution of methanol (46 mL) was 8.7 $\times 10^{-3} \mathrm{~mol} \mathrm{~L}^{-1}$ and the ratio of catalyst/substrate was $2.3 \times 10^{-3}$. The absorbance was continually monitored at $400 \mathrm{~nm}$ for $1 \mathrm{~h}$ using a dipping probe colorimeter.

\section{Heterogeneous catalysis}

Heterogeneous catalysis was performed in a flow cell (Fig. 2) containing the modified graphite felt (10 mm diameter, $12 \mathrm{~mm}$ thickness).

\section{Figure 2}

A fresh solution of $8.7 \times 10^{-3} \mathrm{~mol} \mathrm{~L}^{-1}$ of 3,5-di-tert-butylcatechol in methanol maintained in air at constant stirring and temperature of $25{ }^{\circ} \mathrm{C}$ percolated the porous support with a constant flow rate $\left(3 \mathrm{~mL} \mathrm{~min}^{-1}\right)$ monitored by a Gilson minipuls 2 peristaltic pump. The number of moles of catalyst was determined by cyclic voltammetry for a graphite felt of $10 \mathrm{~mm}$ diameter 
and $12 \mathrm{~mm}$ thickness $\left(1.8 \times 10^{-8} \mathrm{~mol}\right.$ for path $1,8.3 \times 10^{-9} \mathrm{~mol}$ for path 2$)$. The volume of methanol was adjusted to have a concentration of 3,5-di-tert-butylcatechol of $8.7 \times 10^{-3} \mathrm{~mol}$ $\mathrm{L}^{-1}$ with a ratio of catalyst/substrate of $4.5 \times 10^{-5}$ if we considered that the catalyst was in all the solution. In fact, this ratio is $2.3 \times 10^{-3}$ if we considered that the reaction only occurred inside the felt containing the catalyst (volume of solution inside the felt: $0.9 \mathrm{~mL}$ ) The absorbance was continually monitored at $400 \mathrm{~nm}$ for $1 \mathrm{~h}$ using a dipping probe colorimeter.

\subsection{Detection of dihydrogen peroxide in the oxidation reaction}

The quantitative determination of $\mathrm{H}_{2} \mathrm{O}_{2}$ was performed according to the literature [40]. Reaction mixtures were prepared as in the kinetic experiments. After $30 \mathrm{~min}$ of reaction, 46 $\mathrm{mL}$ of $\mathrm{H}_{2} \mathrm{SO}_{4}\left(2 \times 10^{-2} \mathrm{~mol} \mathrm{~L}{ }^{-1}\right)$ was added to stop further oxidation. The quinone was extracted three times with dichloromethane. Four milligrams of KI and a catalytic amount of ammonium molybdate were added. The increase in the $\mathrm{I}_{3}{ }^{-}$absorption band at $353 \mathrm{~nm}(\varepsilon=26$ $000 \mathrm{~L} \mathrm{~mol}^{-1} \mathrm{~cm}^{-1}$ ) was monitored by UV-Vis spectroscopy.

\section{Results and discussion}

\subsection{Derivatization of the graphite felt}

The graphite felt used here as a support has the advantage to combine two interesting properties [31]: a high specific surface area $\left(0.7 \mathrm{~m}^{2} \mathrm{~g}^{-1}\right)$ allowing the immobilization of a high amount of catalyst in a small volume of felt and a good conductivity $\left(2.8\right.$ à $250 \Omega^{-1} \mathrm{~m}^{-1}$ according to the mechanical compression of the felt [41]) facilitating its functionalization by electrochemical methods.

The immobilization of the catalyst was achieved in two different ways (Scheme 2).

\section{Scheme 2}

The first step consists in the functionalization of the graphite felt by electrochemical reduction of diazonium salts [42]. Before introducing the carboxylic acid linker, the immobilization process was investigated with 4-nitrobenzenediazonium salts used for its electroactive $\mathrm{NO}_{2}$ group. The derivatization of the porous support was achieved in a flow cell in $0.5 \mathrm{M} \mathrm{H}_{2} \mathrm{SO}_{4}$ at $-0.2 \mathrm{~V}_{\mathrm{SCE}}$, the graphite felt being used as a working electrode. The volume concentration $\Gamma$ of 
immobilized aryl groups was estimated from cyclic voltammetry analysis of the NHOH/NO reversible system by using the Faraday law (Fig. 1 a). The plot of estimated volume concentration $v s$ time is given in Fig. 1 b. The estimated volume concentration decreased significantly after $30 \mathrm{~min}$ of electrografting. It is well-known with films formed by reduction of 4-nitrobenzenediazonium salts that the electrochemical response of nitro groups stops increasing after a few nanometers [43, 44]. However, the decrease of the electrochemical response is less frequent. It has been attributed to reduction of the nitro groups during the electrografting process [45]. Since, it is well-known that the reduction of diazonium salts is a multilayer process leading to the formation of blocking films [46, 47], the decrease in volume concentration could also be due to slower ion transport within the increasing layers. Therefore, an electrolysis time of $5 \mathrm{~min}$, allowing reaching good volume concentrations without the formation of too thick blocking films, was used in the following experiments for the cathodic reduction of 4-carboxymethyl-benzenediazonium salts.

The second step of the immobilization process consists in the chemical attachment of the copper complex (Scheme 2, path 1) or the ligand (Scheme 2, path 2). We first studied the reactivity of the carboxylic acid function on the support with 4-nitrobenzyl alcohol to optimize the esterification reaction conditions. The carboxylic acid group was first activated by DAST, oxalyl chloride or $\mathrm{SOCl}_{2}$ and then was allowed to react with the nitro species. Interestingly, we observed the formation of two reversible systems after reduction of the nitro group at $-0.5 \mathrm{~V}_{\mathrm{SCE}}$ (Fig. 3 a).

\section{Figure 3}

The system at $0.32 \mathrm{~V}_{\mathrm{SCE}}$ corresponds to the expected $\mathrm{NHOH} / \mathrm{NO}$ couple, showing that the reaction with the alcohol compound was efficient for all the activation modes. We attributed the second system at $0.09 \mathrm{~V}_{\mathrm{SCE}}$ to an azo/hydrazo couple. Indeed, after esterification, no electrochemical signal was observed between 0 and $0.6 \mathrm{~V}_{\text {SCE }}$. A potential sweep between 0 and $-0.5 \mathrm{~V}_{\mathrm{SCE}}$ was necessary for the two reversible systems to appear. After reduction of nitro group into hydroxylamine ( 0 to $-0.5 \mathrm{~V}_{\mathrm{SCE}}$ ), a partial oxidation reaction of $\mathrm{NHOH}$ group into nitroso ( 0 to $0.6 \mathrm{~V}_{\mathrm{SCE}}$ ) could occur, which as soon as it is formed reacts with a hydroxylamine group of its neighbor, giving rise to the formation of an azoxy derivative according to scheme 3 [48]. 
Scheme 3

The cathodic reduction of azoxy compound would then lead to the formation of hydrazo species grafted on the electrode. To our knowledge, the presence of the azo/hydrazo peak has never been observed in literature after reduction of immobilized nitro species and can be attributed to the flexibility of the nitro phenyl group with this immobilization method. Therefore, to compare the three activation modes, it is necessary to consider the two reversible systems (Fig. 3 b). The total volume concentrations of grafted nitro species was calculated by adding two times the volume concentration estimated from the $\mathrm{N}_{2} / \mathrm{N}_{2} \mathrm{H}_{2}$ signal and one time those of $\mathrm{NHOH} / \mathrm{NO}$. The use of thionyl chloride led to the highest volume concentration of grafted species but also to the lowest homogeneity. Since acid fluorides are not very sensitive to moisture and drastic anhydrous conditions are not necessary, we decided to work with DAST in further experiments.

It is interesting to note that the formation of an azo/hydrazo couple would mean that the grafted compounds are enough close together to be able to react as it can be expected with electrografting by diazonium salts, which is known to lead to compact films [42].

After activation of the carboxylic acid with DAST, the complex was directly immobilized on the support according to path 1 or the tripodal ligand was first immobilized and subsequently metallated with $\mathrm{CuCl}_{2}$ according to path 2 (Scheme 2). The grafted complex was analyzed by cyclic voltammetry in acetonitrile (Fig. 4).

Figure 4

Two quasi reversible waves were obtained at 0.54 and $0.51 \mathrm{~V}_{\mathrm{SCE}}$ for paths 1 and 2, respectively. The difference in half-wave potential and wave shape observed for the $\mathrm{Cu}^{\mathrm{II} / \mathrm{I}}$ system between the two immobilization methods reveals that they do not lead to totally identical immobilized complexes. However, in both cases, the potential is anodically shifted compared with the same complex in solution $\left(0.27 \mathrm{~V}_{\mathrm{SCE}}\right.$ [37]). This phenomenon can come from the coordination of the metal, which can be different in solution than when it is grafted due to a rearrangement of the complex after its immobilization. Since we obtained close values of potential for paths 1 and 2, copper is probably coordinated to three nitrogens of tripodal ligands. The difference can come from the nature of the fourth and fifth ligands of the pentacoordinated metal. For example, it can be explained by the coordination of the alcohol 
ending group to the metal in solution, which is not possible in heterogeneous conditions since it is involved in an ester bond. Volume concentrations of immobilized copper complex were estimated from the $\mathrm{Cu}^{\mathrm{I} / \mathrm{I}}$ system to $1.8 \times 10^{-8}$ and $8.3 \times 10^{-9} \mathrm{~mol} \mathrm{~cm}^{-3}$ for paths 1 and 2 , respectively. The grafting process is less efficient for path 2 , showing that the metalation reaction is not quantitative in heterogeneous conditions.

\subsection{Heterogeneous catalysis}

The catecholase activity of the immobilized copper(II) complex was studied by testing its ability to catalyze 3,5-di-tert-butylcatechol in a flow cell (Fig. 2). This substrate with two bulky tert-butyl substituents on the ring is usually used since it is highly stable and it has a low quinone-catechol reduction potential that makes it easily oxidized to the corresponding $o$ quinone. The solution with the substrate goes through the modified graphite felt at a constant rate thanks to a peristaltic pump. The kinetics of formation of 3,5-di-tert-butylquinone in the presence of the catalyst was continually monitored using a dipping probe colorimeter, since the quinone presents a strong absorption band at $400 \mathrm{~nm}$. The reaction was performed for $1 \mathrm{~h}$ at constant agitation and temperature of $25{ }^{\circ} \mathrm{C}$ and with a catalyst/substrate ratio of $4.5 \times 10^{-5}$. These conditions correspond to the beginning of the conversion of catechol into quinone. Since the volume concentrations of grafted catalyst according to paths 1 and 2 are slightly different, the volume of methanol is calculated to maintain constant the concentration of substrate in solution, allowing the comparison of the two methods. A blank was also carried out with a graphite felt only modified by the linker. The results are given in fig. 5 . The rates were determined from the slope of the tangent to the absorbance $v s$ time curve (Table 1).

Figure 5

Table 1

The catalytic activity of the graphite felts containing the copper complex is significantly higher than the blank, showing that the catalyst is still active when it is immobilized. However, the activity of the felt modified according to path 2 is significantly lower than those of path 1 . This result can be correlated with cyclic voltammograms that shows some significant differences between the two immobilization methods. As already observed with copper complexes prepared by immobilization of a ligand and subsequent reaction with $\mathrm{Cu}^{2+}$ 
[5], a possible explanation can come from the coordination mode that can be different in heterogeneous conditions. For example, the metal can be coordinated to three nitrogens of two close tripodal ligands instead of only one, giving rise to lower catalytic activity.

For comparison, the catalytic reaction was performed with the catalyst dissolved in solution with the same concentration of catechol and with a ratio of catalyst/substrate of $2.3 \times 10^{-3}$ (Fig. 6).

Figure 6

The catalytic activity in supported catalysis was two times higher than when the catalyst was in solution (Table 1). This result is interesting since the amount of catalyst used in supported catalysis was 50 times lower than in homogeneous catalysis $\left(1.8 \times 10^{-8} \mathrm{~mol}\right.$ for supported catalysis, $9 \times 10^{-7} \mathrm{~mol}$ for homogeneous catalysis). It highlights the advantage of continuous flow catalysis, since a small amount of the substrate is actually forced into intimate contact with an "excess" of catalyst favoring higher conversions and lower reaction time. Since the catalyst is concentrated in a small volume in heterogeneous catalysis, we only consider the volume of solution inside the graphite felt sample (measured to be $0.9 \mathrm{~mL}$ for a graphite felt of $10 \mathrm{~mm}$ diameter and $12 \mathrm{~mm}$ thickness) to compare with the catalyst in solution. Thus, the estimated real ratio of catalyst/substrate is $2.3 \times 10^{-3}$, which is the value that we used in homogeneous catalysis. Since the concentration of catechol is also the same in both catalytic conditions, the better catalytic activity of the grafted complex is not only due to the continuous flow mode. Two phenomenons can be responsible for the enhancement of the catalytic activity. First, as observed in cyclic voltammetry (Fig. 4), the half-wave potential of the immobilized copper complex is anodically shifted by $0.3 \mathrm{~V}$ compared with the same compound in solution. As explained previously, a possible explanation is the coordination of the electron-donating $\mathrm{OH}$ group to the metal, when the catalyst is in solution. Thus, the resulting increase in the steric hindrance around the copper atom and the more difficult reduction of the $\mathrm{Cu}^{\mathrm{II}}$ intermediate in $\mathrm{Cu}^{\mathrm{I}}$ in the catalytic cycle would prevent the coordination of catechol, affecting the catalytic activity of the complex. Second, it is known that dinuclear copper complexes show better catecholase activity than their mononuclear analogs due to the close distance between the two copper atoms, as in catechol oxidase [49-51]. Thus, the enhancement of the catalytic activity when the complex is immobilized could be due to the proximity of two $\mathrm{Cu}$ atoms induced by the support. 
We have previously observed for the mononuclear tripodal copper complexes that the mechanism of the reaction involves a two-electron reduction of $\mathrm{O}_{2}$ in $1 \mathrm{~mol}$ of dihydrogen peroxide with the formation of $1 \mathrm{~mol}$ of 3,5-di-tert-butylquinone [37]. After a reaction with the same complex in continuous flow catalysis, a quantitative analysis of hydrogen peroxide by oxidation of $\mathrm{I}^{-}$(see section 2) was performed with $5 \times 10^{-2} \mathrm{~mol} \mathrm{~L}^{-1}$ concentration of catechol. $1.5 \pm 0.1 \mathrm{~mol} \mathrm{H}_{2} \mathrm{O}_{2}$ was shown to be produced per mole of 3,5-di-tert-butylcatechol. This result shows that the mechanism is not the same than the natural enzyme, which involves the oxidation of two molecules of catechol and the four electron reduction of dioxygen in water. However the formation of $\mathrm{H}_{2} \mathrm{O}_{2}$ does not allow differentiating between a mechanism involving mononuclear or dinuclear complexes. Indeed, the formation of $\mathrm{H}_{2} \mathrm{O}_{2}$ has been already observed with dinuclear copper complexes and different mechanisms have been proposed [52]. Recently, it has been suggested that the formation of hydrogen peroxide is due to the binding of the doubly deprotonated catecholate to only one copper atom leading to similar mechanism than mononuclear complexes [53, 54]. This would occur when the distance between two copper atoms is too long. Since the grafting process allowed the formation of azo/hydrazo species with $\mathrm{NO}_{2}$-containing species, the proximity of two immobilized tripodal copper complexes is probable. However, it is possible that the steric hindrance due to tripodal ligands does not allow the complexes to adopt a configuration favoring the close proximity of the two copper atoms.

Another important feature of continuous flow catalysis compared with unsupported one is the excess of $\mathrm{H}_{2} \mathrm{O}_{2}$ produced during the reaction. If this result is still unclear for the moment, it seems that the quinone is not the only product resulting from the oxidation of catechol in heterogeneous catalysis.

\section{Conclusion}

A tripodal copper complex was immobilized onto graphite felt for continuous flow catalysis applications. The immobilization method first required the functionalization of the support. This was achieved by electrochemical reduction of 4-carboxymethylbenzenediazonium salts, leading to the covalent attachment of the linker containing carboxylic acid groups. In a second step, either the complex (path 1) or the ligand (path 2) was immobilized by esterification reaction between the $\mathrm{COOH}$-containing support and the alcohol ending groups of the tripodal ligand. A subsequent metalation reaction performed with $\mathrm{CuCl}_{2}$ was necessary for path 2 . The 
modification process, optimized by using nitro compounds as well-known electroactive species, led to volume concentrations of $1.8 \times 10^{-8}$ and $8.3 \times 10^{-9} \mathrm{~mol} \mathrm{~cm}^{-3}$ for paths 1 and 2 , respectively, with a good homogeneity in the distribution of immobilized complexes inside the felt. Interestingly, when nitro compounds were immobilized by esterification reaction on the functionalized support, cyclic voltammetry analyses showed, after cathodic reduction at $0.5 \mathrm{~V}_{\mathrm{SCE}}$, the presence of an unexpected reversible system attributed to $\mathrm{N}_{2} / \mathrm{N}_{2} \mathrm{H}_{2}$ couple. This result seems to reveal that some of the immobilized molecules are enough close to react together. Continuous flow catalysis with immobilized complexes gave better results than a graphite felt modified by cathodic reduction of 4-carboxymethyl-benzenediazonium salts, used as a reference. This underlines that the complexes are still catalytically active when they are immobilized. However, better results were obtained with graphite felt modified according to path 1 . This discrepancy in catalytic activity has been attributed to different coordination modes, since the metal can be coordinated for example to two close ligands when they are attached on a support. Comparison of both catalytic processes underlined the interest of the flow system that gives better conversion yields with the use of less catalyst. With the same ratio of catalyst/substrate (calculated in the felt volume) and catechol concentration, heterogeneous catalysis exhibited better results than homogeneous one. Several hypotheses have been proposed to explain this interesting result. First, since the potential of the immobilized complex is anodically shifted compared with the same compound in solution, a possible explanation is a different coordination mode when the complex is immobilized. For example, the alcohol ending group of the complex involved in an ester bond when it is immobilized, will not be coordinated to the copper atom, as it can be in solution. Since dinuclear complexes are known to give better catalytic activity than their mononuclear analogs, the proximity of two grafted complexes constitutes another argument. This is emphasized by cyclic voltammetry experiments performed with nitro species that tend to show the closeness of the immobilized molecules. The presence of $\mathrm{H}_{2} \mathrm{O}_{2}$ after catalysis does not allow distinction between mechanisms involving dinuclear or mononuclear complexes but underlines that the four electron reduction of $\mathrm{O}_{2}$ in water as with catechol oxidase does not occur.

\section{References}

L. M. Mirica, X. Ottenwaelder, T. D. P. Stack, Chem. Rev. 104 (2004) 1013. 
[2] W. B. Tolman, Acc. Chem. Res. 30 (1997) 227.

[3] T. Klabunde, C. Eicken, J. C. Sacchettini, B. Krebs, Nat. Struct. Mol. Biol. 5 (1998) 1084.

[4] K. A. Magnus, H. Tonthat, J. E. Carpenter, Chem. Rev. 94 (1994) 727.

[5] G. Grigoropoulou, K. C. Christoforidis, M. Louloudi, Y. Deligiannakis, Langmuir 23 (2007) 10407.

[6] M. Louloudi, Y. Deligiannakis, N. Hadjiliadis, Inorg. Chem. 37 (1998) 6847.

[7] M. Louloudi, K. Mitopoulou, E. Evaggelou, Y. Deligiannakis, N. Hadjiliadis, J. Mol. Catal. A: Chem. 198 (2003) 231.

[8] D. Zois, C. Vartzouma, Y. Deligiannakis, N. Hadjiliadis, L. Casella, E. Monzani, M. Louloudi, J. Mol. Catal. A: Chem. 261 (2007) 306.

[9] C. H. Lee, S. T. Wong, T. S. Lin, C. Y. Mou, J. Phys. Chem. B 109 (2005) 775.

[10] C. H. Lee, H. C. Lin, S. H. Cheng, T. S. Lin, C. Y. Mou, J. Phys. Chem. C 113 (2009) 16058.

[11] B. Dutta, S. Jana, R. Bera, P. K. Saha, S. Koner, Appl. Catal. A: Gen. 318 (2007) 89.

[12] P. K. Saha, B. Dutta, S. Jana, R. Bera, S. Saha, K. Okamoto, S. Koner, Polyhedron 26 (2007) 563.

[13] P. K. Sahaa, S. Koner, Inorg. Chem. Commun. 7 (2004) 1164.

[14] I. U. Castro, D. C. Sherrington, A. Fortuny, A. Fabregat, F. Stuber, J. Font, C. Bengoa, Catal. Today 157 (2010) 66.

[15] I. U. Castro, F. Stuber, A. Fabregat, J. Font, A. Fortuny, C. Bengoa, J. Hazard. Mater. 163 (2009) 809.

[16] S. Chavan, D. Srinivas, P. Ratnasamy, J. Catal. 192 (2000) 286.

[17] S. Deshpande, D. Srinivas, P. Ratnasamy, J. Catal. 188 (1999) 261.

[18] R. Robert, P. Ratnasamy, J. Mol. Catal. A: Chem. 100 (1995) 93.

[19] S. Seelan, A. K. Sinha, Appl. Catal. A: Gen. 238 (2003) 201.

[20] A. V. Kucherov, N. V. Kramareva, E. D. Finashina, A. E. Koklin, L. M. Kustov, J. Mol. Catal. A: Chem. 198 (2003) 377.

[21] S. Striegler, M. G. Gichinga, M. Dittelt, Org. Lett. 10 (2008) 241.

[22] M. A. Bizeto, W. A. Alves, C. A. S. Barbosa, A. Ferreira, V. R. L. Constantino, Inorg. Chem. 45 (2006) 6214.

[23] N. R. Suja, N. Sridevi, K. K. M. Yusuff, Kinet. Catal. 45 (2004) 337.

[24] M. Mureseanu, V. Parvulescu, R. Ene, N. Cioatera, T. D. Pasatoiu, M. Andruh, J. Mater. Sci. 44 (2009) 6795.

[25] F. Geneste, C. Moinet, J. Electroanal. Chem. 594 (2006) 105.

[26] F. Geneste, C. Moinet, S. Ababou-Girard, F. Solal, New J. Chem. 29 (2005) 1520.

[27] F. Geneste, C. Moinet, S. Ababou-Girard, F. Solal, Inorg. Chem. 44 (2005) 4366.

[28] F. Geneste, C. Moinet, New J. Chem. 29 (2005) 269. 
[29] F. Geneste, C. Moinet, G. Jezequel, New J. Chem. 26 (2002) 1539.

[30] F. Geneste, C. Moinet, New J. Chem. 28 (2004) 722.

[31] F. Geneste, M. Cadoret, C. Moinet, G. Jezequel, New J. Chem. 26 (2002) 1261.

[32] R. Nasraoui, D. Floner, C. Paul-Roth, F. Geneste, J. Electroanal. Chem. 638 (2010) 9.

[33] J. Wegner, S. Ceylan, A. Kirschning, Chem. Commun. 47 (2011) 4583.

[34] U. Hintermair, G. Francio, W. Leitner, Chem. Commun. 47 (2011) 3691.

[35] A. Kirschning, W. Solodenko, K. Mennecke, Chem. Eur. J. 12 (2006) 5972.

[36] G. Jas, A. Kirschning, Chem. Eur. J. 9 (2003) 5708.

[37] R. Marion, M. Zaarour, N. A. Qachachi, N. M. Saleh, F. Justaud, D. Floner, O. Lavastre, F. Geneste, J. Inorg. Biochem. 105 (2011) 1391.

[38] C. Bourdillon, M. Delamar, C. Demaille, R. Hitmi, J. Moiroux, J. Pinson, J. Electroanal. Chem. 336 (1992) 113.

[39] C. Moinet, J. Phys. IV 4 (1994) 175.

[40] A. Neves, L. M. Rossi, A. J. Bortoluzzi, B. Szpoganicz, C. Wiezbicki, E. Schwingel, Inorg. Chem. 41 (2002) 1788.

[41] E. O. Vilar, N. L. De Freitas, F. R. De Lirio, F. B. De Sousa, Braz. J. Chem. Eng. 15 (1998) 295.

[42] D. Belanger, J. Pinson, Chem. Soc. Rev. 40 (2011) 3995.

[43] P. A. Brooksby, A. J. Downard, J. Phys. Chem. B 109 (2005) 8791.

[44] P. A. Brooksby, A. J. Downard, Langmuir 20 (2004) 5038.

[45] J. Ghilane, M. Delamar, M. Guilloux-Viry, C. Lagrost, C. Mangeney, P. Hapiot, Langmuir 21 (2005) 6422.

[46] A. Adenier, C. Combellas, F. Kanoufi, J. Pinson, F. I. Podvorica, Chem. Mater. 18 (2006) 2021.

[47] A. C. Cruickshank, E. S. Q. Tan, P. A. Brooksby, A. J. Downard, Electrochem. Commun. 9 (2007) 1456.

[48] M. Baizer, H. Lund, Organic Electrochemistry, Decker, Marcel, New York, 1991.

[49] C. H. Kao, H. H. Wei, Y. H. Liu, G. H. Lee, Y. Wang, C. J. Lee, J. Inorg. Biochem. 84 (2001) 171.

[50] M. R. Malachowski, M. G. Davidson, Inorg. Chim. Acta 162 (1989) 199.

[51] U. Casellato, S. Tamburini, P. A. Vigato, A. De Stefani, M. Vidali, D. E. Fenton, Inorg. Chim. Acta 69 (1983) 45.

[52] I. A. Koval, P. Gamez, C. Belle, K. Selmeczi, J. Reedijk, Chem. Soc. Rev. 35 (2006) 814.

[53] T. Plenge, R. Dillinger, L. Santagostini, L. Casella, F. Tuczek, Z. Anorg. Allg. Chem. 629 (2003) 2258.

[54] J. Ackermann, F. Meyer, E. Kaifer, H. Pritzkow, Chem. Eur. J. 8 (2002) 247. 


\section{Figure captions.}

Figure 1: a) Voltammogram of $\mathrm{NHOH} / \mathrm{NO}$ system in $0.5 \mathrm{M} \mathrm{H}_{2} \mathrm{SO}_{4}$ for nitro species grafted on the graphite surface during $5 \mathrm{~min}$, after two potential sweeps between $0.6 \mathrm{~V}$ and $-0.5 \mathrm{~V}_{\mathrm{SCE}}$. Scan rate: $0.1 \mathrm{~V} \mathrm{~s}^{-1}$. Only the bottom of the wave (e. $g$. hatched area) was considered for the calculation of the volume concentration using the Faraday law b) volume concentration of immobilized 4-nitrobenzenediazonium salt vs electrolysis time. Error bars are estimated from 2 samples taken in a same grafted felt.

Figure 2: a Graphite felt (10 mm diameter and $12 \mathrm{~mm}$ thickness) modified with the tripodal complex $\left(1.8 \times 10^{-8} \mathrm{~mol}\right)$, b peristaltic pump at $3 \mathrm{~mL} \mathrm{~min}^{-1}$, c solution of $8.7 \times 10^{-3} \mathrm{~mol} \mathrm{~L}^{-1}$ of 3,5-di-tert-butylcatechol in methanol.

Figure 3: a) Voltammogram of $\mathrm{NHOH} / \mathrm{NO}$ and $\mathrm{N}_{2} / \mathrm{N}_{2} \mathrm{H}_{2}$ systems in $0.5 \mathrm{M} \mathrm{H}_{2} \mathrm{SO}_{4}$ from nitro species chemically attached on the carboxylic acid functionalized graphite felt, after two potential sweeps between $0.6 \mathrm{~V}$ and $-0.5 \mathrm{~V}_{\mathrm{SCE}}$. Scan rate: $0.1 \mathrm{~V} \mathrm{~s}^{-1} \mathrm{~b}$ ) Total volume concentration of immobilized 4-nitrobenzyl alcohol by using DAST, oxalyl chloride and $\mathrm{SOCl}_{2}$ for carboxylic acid activation. Error bars are estimated from two samples taken in a same grafted felt.

Figure 4: Cyclic voltammograms of the electrode modified according to paths $1(-)$ and 2 (----) in acetonitrile $+0.1 \mathrm{M} \mathrm{Bu}_{4} \mathrm{NPF}_{6}$. Scan rate $0.02 \mathrm{~V} \mathrm{~s}^{-1}$.

Figure 5: Plot of absorbance vs time for the oxidation of 3,5-di-tert-butylcatechol performed at $25^{\circ} \mathrm{C}$ in $\mathrm{MeOH}$ and catalyzed by the immobilized complex (path 1) (path 2) $\boldsymbol{\nabla}$. A blank was performed with graphite felt modified by 4-carboxymethylbenzenediazonium salts Error bars are based on two reproducibility measurements.

Figure 6: Plot of absorbance vs time for the oxidation of 3,5-di-tert-butylcatechol performed at $25^{\circ} \mathrm{C}$ in $\mathrm{MeOH}$ and catalyzed by the copper complex in solution $\bullet$ or in heterogeneous catalysis - A blank was performed with graphite felt modified by 4carboxymethylbenzenediazonium salts $\boldsymbol{\Lambda}$. Error bars are based on two reproducibility measurements.

\section{Scheme captions.}


Scheme 1: Active site of type-3 copper proteins

Scheme 2: Immobilization of the catalyst on graphite felt

Scheme 3: Proposed mechanism for the suspected formation of azo species during the electrochemical analysis of immobilized nitro derivatives

Table 1: Catalytic activity of the copper (II) complex

\begin{tabular}{lllll}
\hline & Blank & In solution & \multicolumn{2}{l}{$\begin{array}{l}\text { Immobilized } \\
\text { complex }\end{array}$} \\
& & & Path 1 & Path 2 \\
\hline $\begin{array}{l}\text { Rate / } \\
\times 10^{8} \mathrm{~mol}^{-1} \mathrm{~L}\end{array}$ & 0.20 & 3.66 & 7.83 & 1.95 \\
$\mathrm{~s}^{-1}$ & & & & \\
\hline
\end{tabular}

\section{Scheme 1}

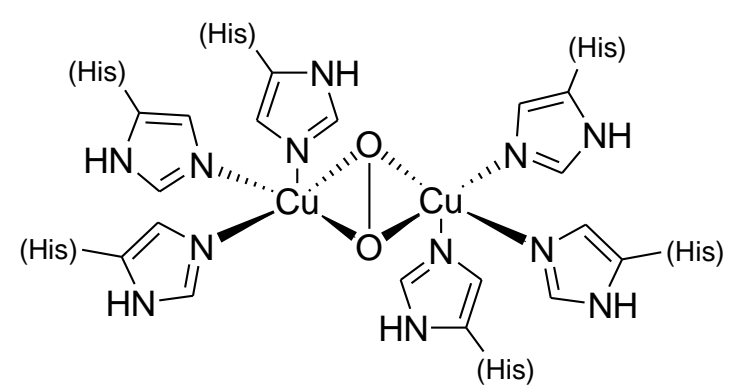

Type 3

Scheme 2

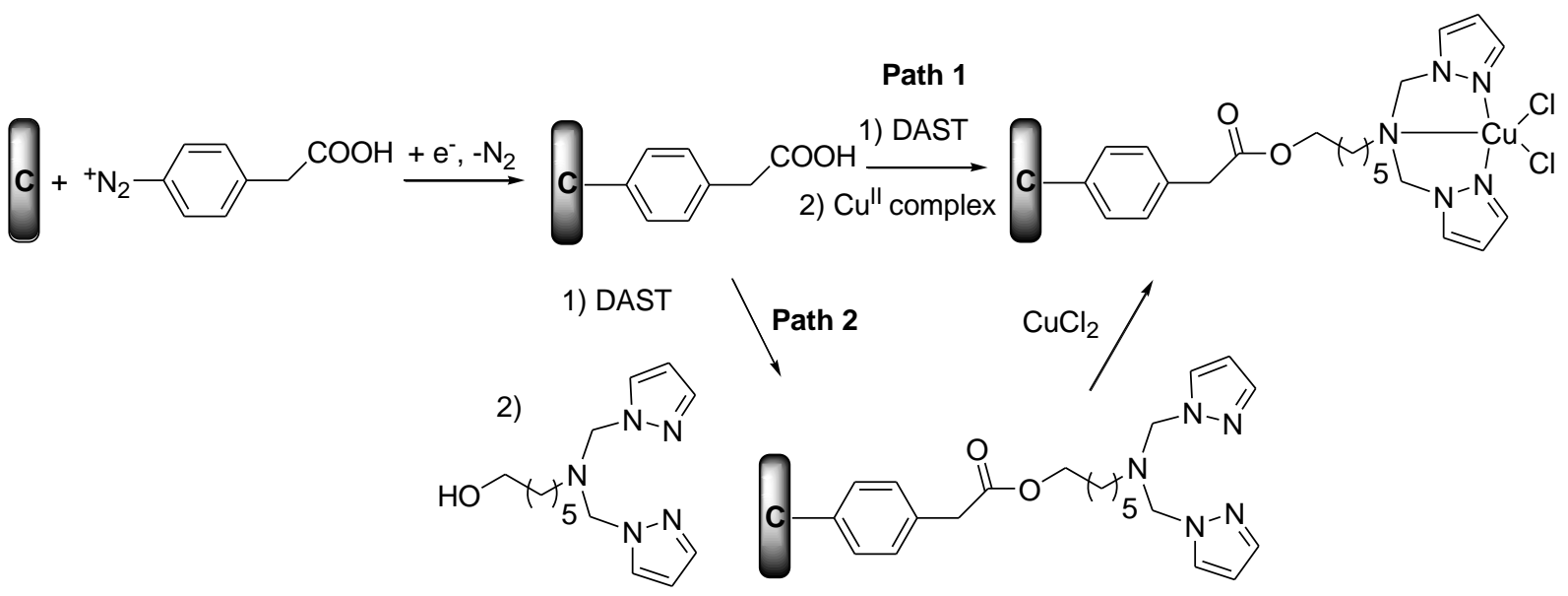


Scheme 3

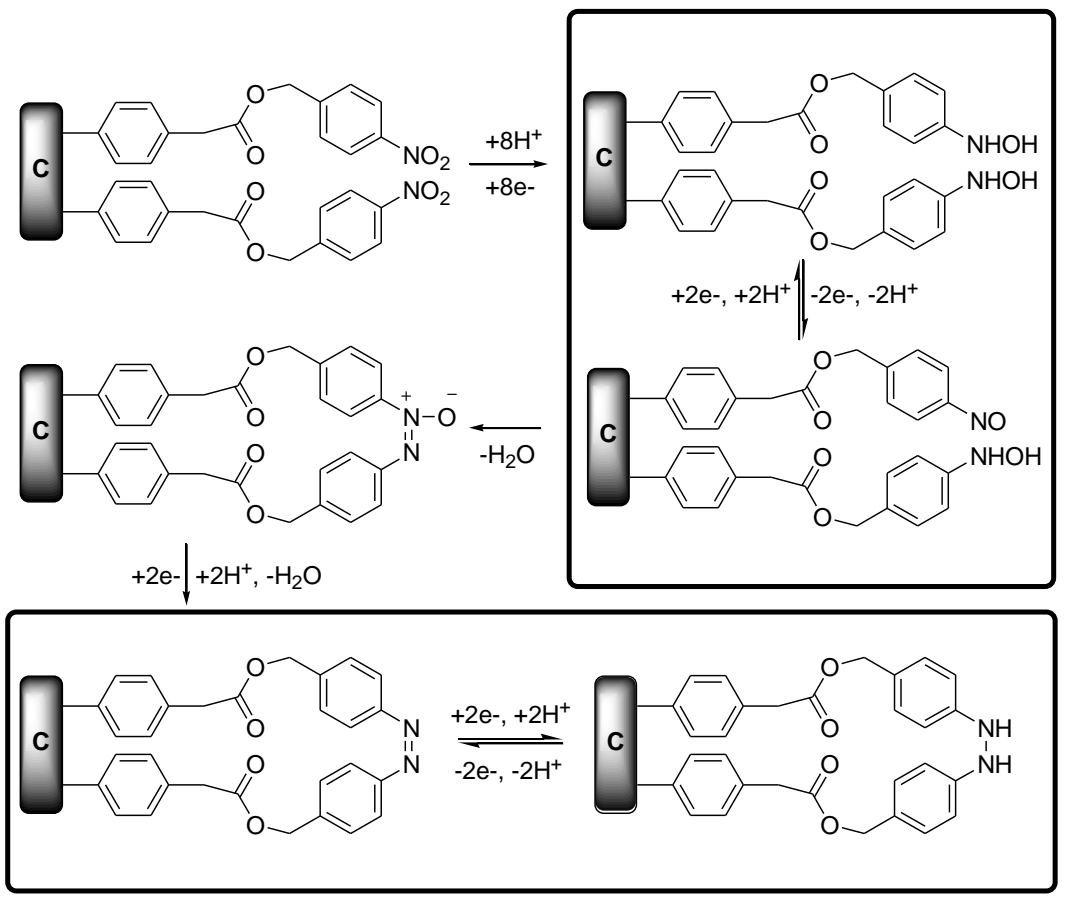


Figure 1
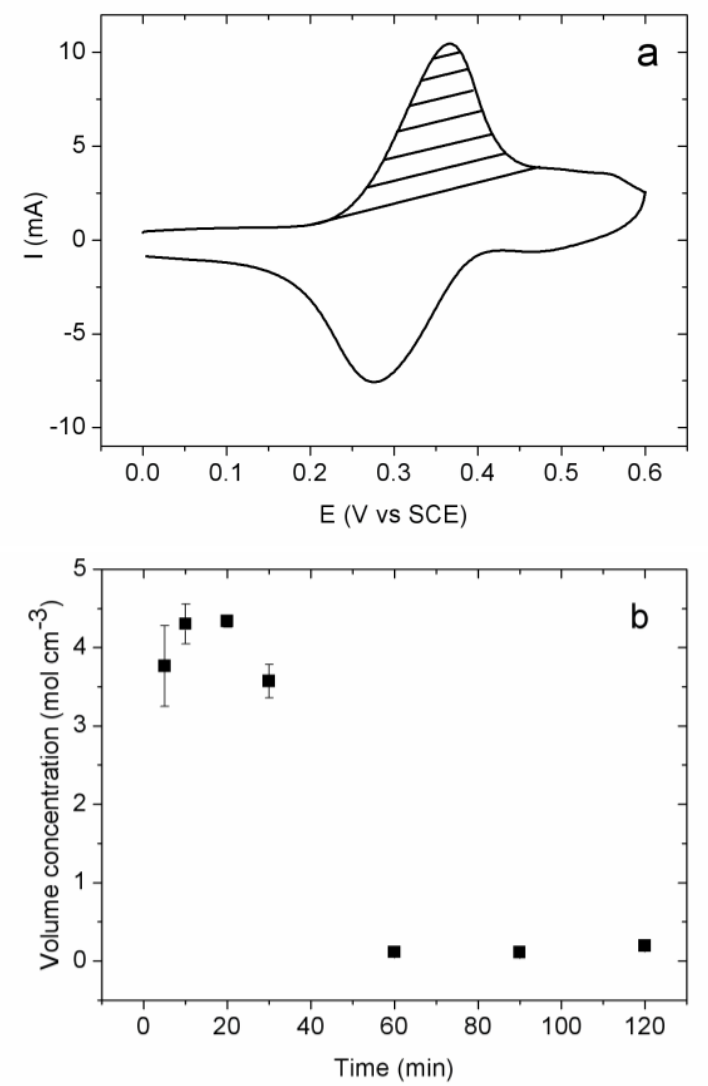

Figure 2

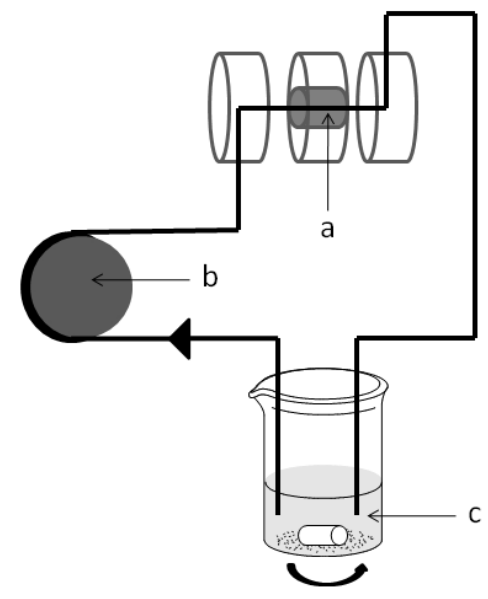


Figure 3
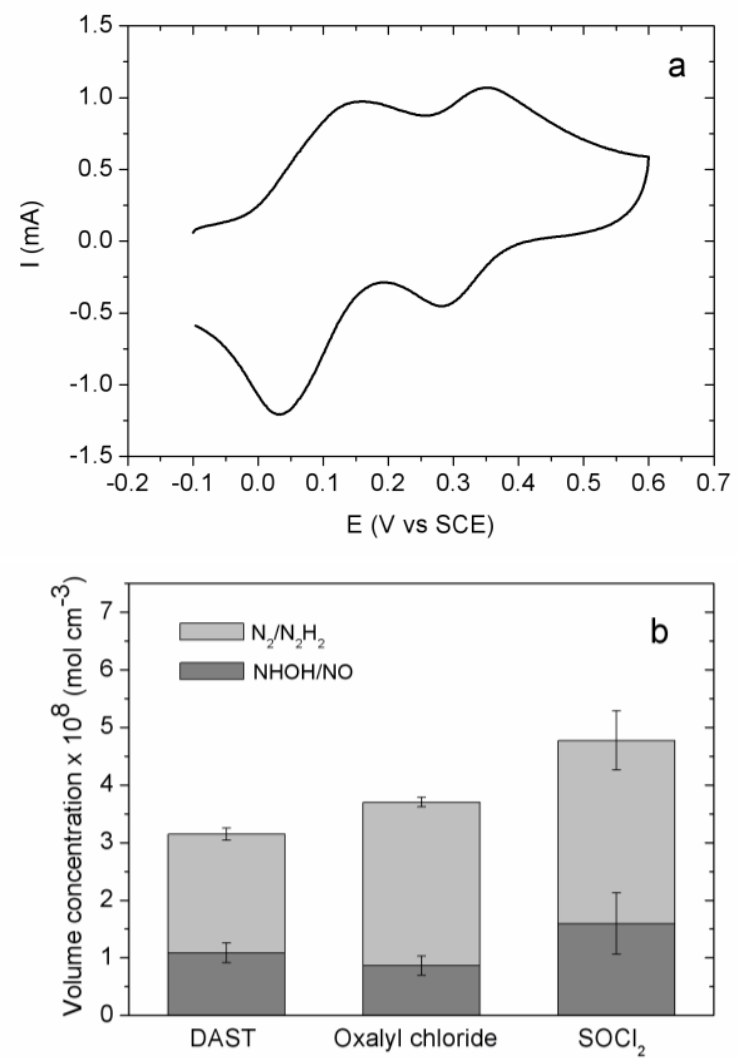

Figure 4

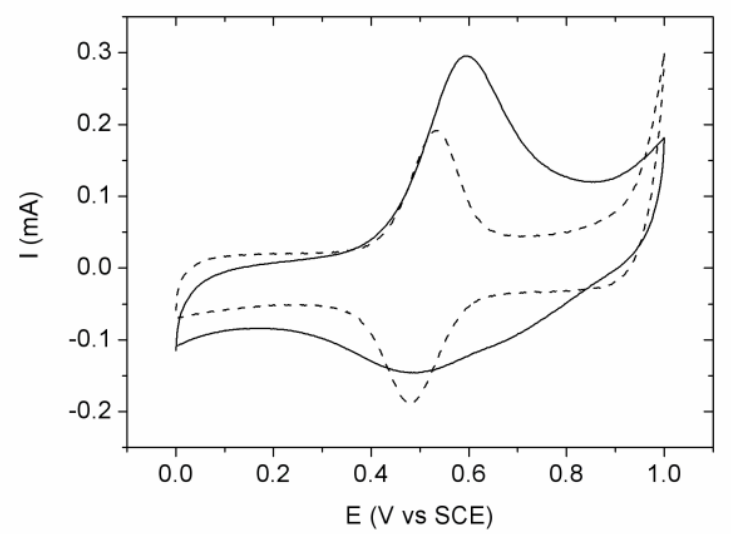


Figure 5

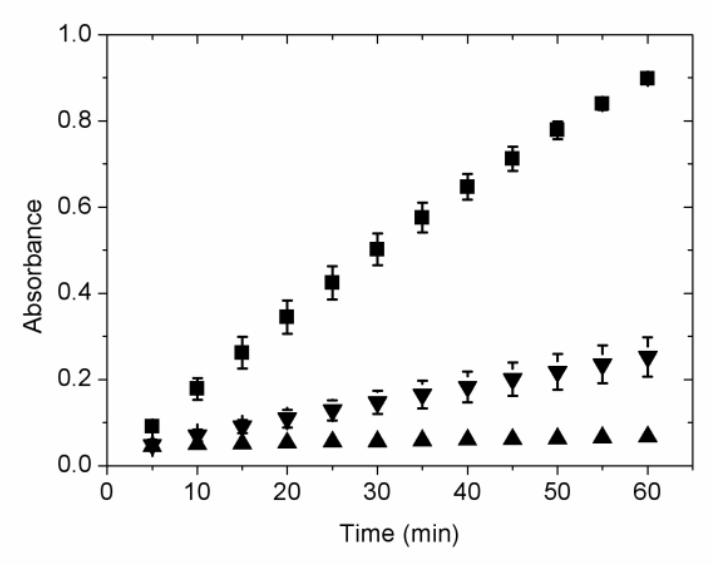

Figure 6

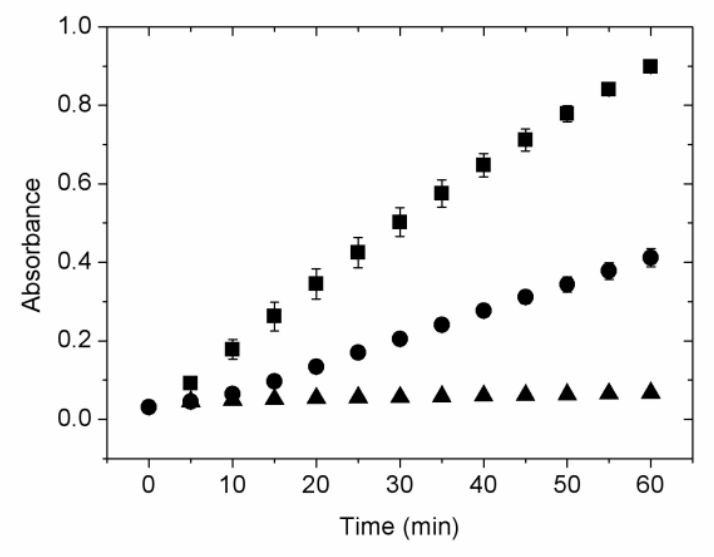

